\title{
Soil Salinity between 1992 and 2000 in Hungary
}

\author{
${ }^{1}$ D. KOVÁCS, ${ }^{1}$ T. TÓTH and ${ }^{2}$ P. MARTH \\ ${ }^{1}$ Research Institute for Soil Science and Agricultural Chemistry (RISSAC) of the \\ Hungarian Academy of Sciences, Budapest, and \\ ${ }^{2}$ Center for Plant and Soil Conservation, Budapest
}

\section{Introduction}

Soil salinization, a process typically caused by sodium salts, is one of the major degradation forms. Occurring in natural conditions and on intensively cropped areas as well, it is a remarkable process that affects some $5 \%$ of the total surface area of the continents.

Soil salinization is a characteristic degradation form of Hungarian soils (SzABOLCS, 1974) as shown by Fig 1. On this figure the most saline soil is Solonchak, a saline soil type. Solonchak-solonetz is an alkaline saline-sodic soil type. Meadow solonetz and Meadow solonetz turning into steppe formation are two sodic soil types, the latter having a deeper Natric B horizon. Solonetzic meadow soil is a hydromorphic soil type, sometimes a Vertisol, with high exchangeable sodium content (SZABOLCS, 1966). Large areas of saline and sodic soils are now under nature protection as grasslands due to their unique vegetation and fauna (MOLNÁR \& BORHIDI, 2003). A considerable surface area with soils surpassing the limit of $0.1 \%$ salt concentration for saline soils, however, is utilized as cropland. As a consequence of irrigation or a rise in the groundwater level these soils may become more saline and limit agricultural activity (TóTH \& BLASKÓ, 1998).

In order to follow-up the tendencies of soil degradation processes, monitoring systems have been established in many countries. Soil salinization is a process that is probably best characterized by soil monitoring networks, as the salt concentration of soils changes quite quickly.

In the present study data from the Hungarian Soil Information and Monitoring System (Fig, 2) were used for determining the overall tendency of salinization in Hungary in recent years: is there an increase or decrease in soil salt concentration? What are the most important background variables affecting the changes in salinity? Compared to an earlier report by KovÁcs et al. (2006), in this paper emphasis is laid on the spatial aspects of soil salinity changes.

Correspondence to: TIBOR TÓTH, Research Institute for Soil Science and Agricultural Chemistry of the Hungarian Academy of Sciences, H-1022 Budapest, Herman Ottó út 15. Hungary.E-mail: tibor@rissac.hu 


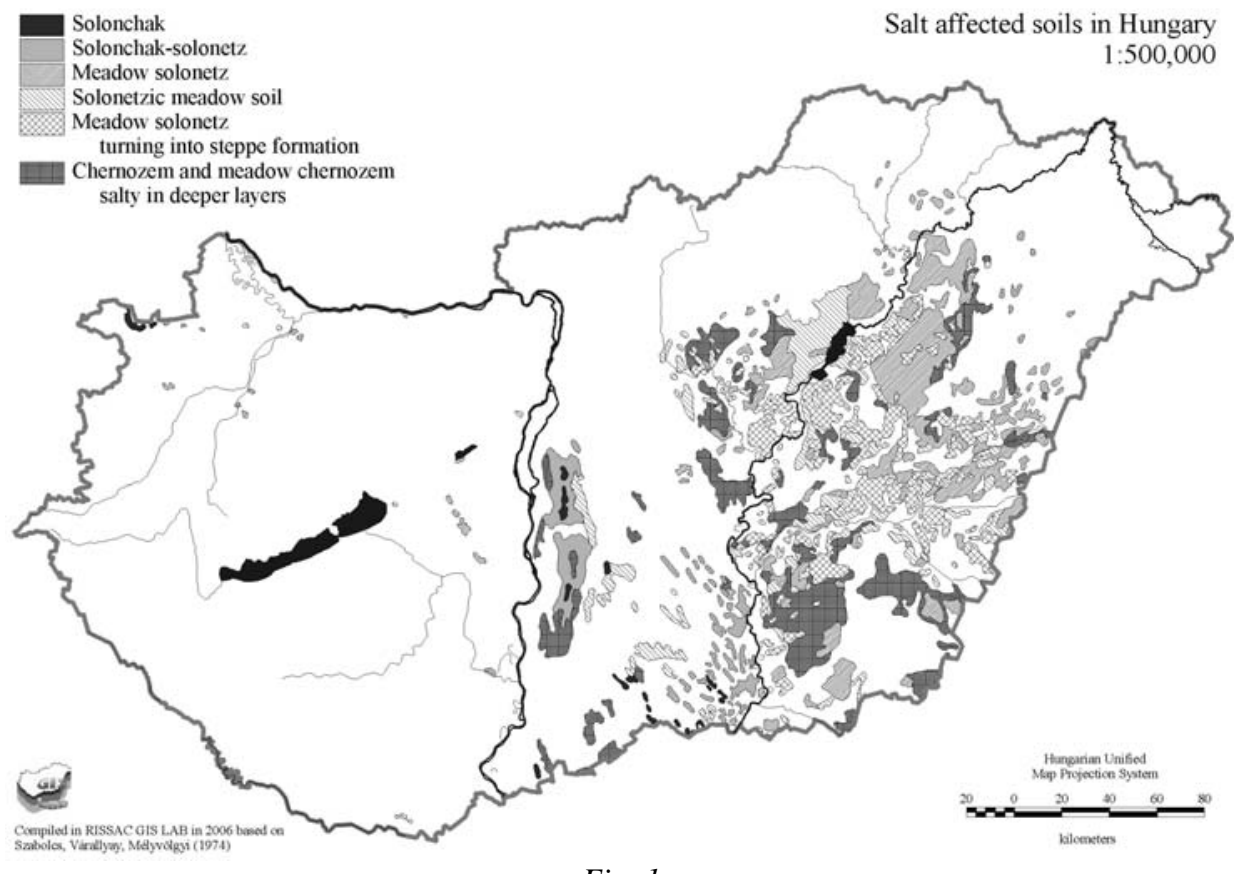

Fig. 1

Map of salt affected soils in Hungary

\section{Materials and Methods}

In the Hungarian Soil Information and Monitoring System the sampling period is 1, 3 or 6 years (VÁRALLYAY et al., 1995) according to the soil type and variable. A parameter was selected that is analyzed with yearly frequency in each genetic soil horizon: soil salt concentration.

The system consists of 1236 points (Fig. 2) representing the geographical regions of the country as well as different land use types. Among those, 865 points are in agricultural lands. The first period of monitoring was carried out between 1992 and 2000 by successive sampling of the soils' genetic horizons at one point identified with a simple Global Positioning Satellite device with the lateral precision of 5-10 $\mathrm{m}$. The present paper treats only salt affected soils, which are found typically in the Great Hungarian Plain, that is the valley of the Danube and Tisza Rivers. As characteristic for the country, the most saline and sodic profiles were located on grassland and the less saline ones on cropland.

The points were sampled every year between 15 September and 15 October from the depths of the soil genetic horizons, which were established during the 1992 survey and the samples were dried and analyzed (VÁRALLYAY et al., 1995). Soil salt concentration was determined by measuring the electrical conductivity of nearly water-saturated paste (reaching the lower plasticity status as defined by Arany, or $\mathrm{K}_{\mathrm{A}}$ value). 


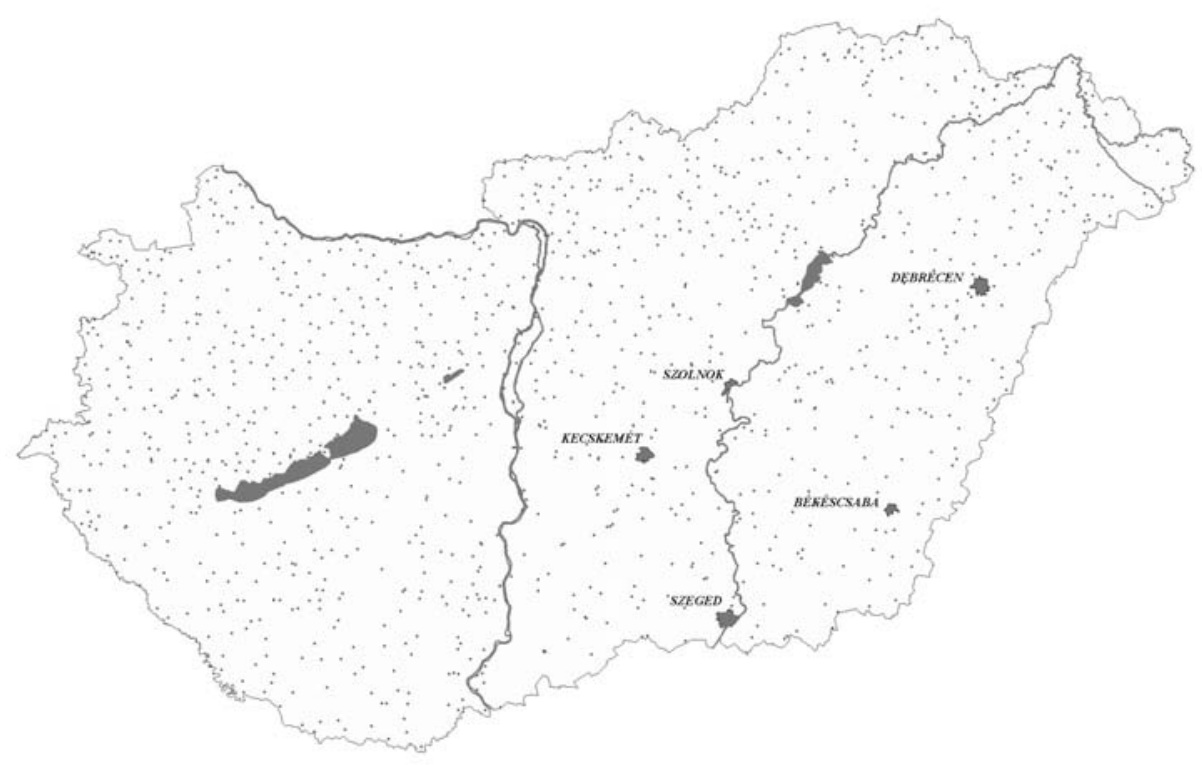

Fig. 2

Sampling points of the Hungarian Soil Information and Monitoring System and location of observation stations for groundwater depth and meteorology

Table 1

Distribution of profiles monitored in areas belonging to groundwater observation stations, indicating the pattern of yearly soil salinity change

\begin{tabular}{|l|c|c|c|c|c|c|}
\hline \multirow{2}{*}{$\begin{array}{c}\text { Pattern of } \\
\text { yearly } \\
\text { salinity } \\
\text { change }\end{array}$} & Békéscsaba & Debrecen & Kecskemét & Szeged & Szolnok & $\begin{array}{c}\text { Active } \\
\text { Margin }\end{array}$ \\
\cline { 2 - 7 }$/$ & 6 & 2 & 2 & 3 & 3 & 16 \\
& 0 & 0 & 0 & 0 & 0 & 0 \\
\hline & 0 & 3 & 4 & 0 & 1 & 8 \\
- & 2 & 3 & 1 & 1 & 1 & 8 \\
M & 2 & 5 & 4 & 1 & 2 & 14 \\
N & 0 & 0 & 0 & 0 & 0 & 0 \\
V & 0 & 4 & 0 & 0 & 1 & 5 \\
$\Lambda$ & 2 & 3 & 2 & 0 & 1 & 8 \\
W & 0 & 4 & 2 & 2 & 1 & 9 \\
Active & 12 & 24 & 15 & 7 & 10 & 68 \\
Margin & 12 & & & 0 & \\
\hline
\end{tabular}

Remark: The letters' main form shows the pattern of yearly changes in soil salinity in the $2^{\text {nd }}$ and $3^{\text {rd }}$ genetic horizon during the monitoring period between 1992 and 2000 
The mechanism of soil salinization is basically well understood for the conditions of the Great Hungarian Plain. Earlier the most important factors affecting soil salinization had been pointed out for the region. Single most important factors are the depth of saline groundwater (DARAB, 1967) and the salt concentration of the groundwater itself, as it has been shown for other regions as well (FULLERTON \& PAWLUK, 1987, GATES et al., 2002.). The resulting soil salinity is affected by the continuous changes in atmospheric conditions (VÁRALLYAY, 1966).

For the present study the most changeable parameters, the meteorological variables and the groundwater depth were selected as background parameters, which have the greatest effect on soil salinization. The groundwater data were collected from published data of the Water Resources Research Centre (VITUKI), Budapest. Data of the following groundwater observation wells were used: Békéscsaba Well No. 2817, Kecskemét Well No. 1391, Szeged Well No. 2484, Szolnok Well No. 2214, Debrecen Well No. 2609. Meteorological data were obtained for the same settlements with the contribution of the Department of Meteorology of the Szeged University and the Southern Transdanubian Regional Center of the Hungarian Meteorological Service.

The patterns of yearly soil salinity changes often showed peaks that were unexplainable by the background parameters, these are evident effects of spatial variability, which are not completely unavoidable with repeated borings based on a simple GPS device. The independent study between 1997 and 2002 by TóTH and KUTI (2002) in a quite homogeneous area of a solonetz soil indicated that the yearly scatter (of October as shown by circles on Fig. 3) in the second genetic horizon was

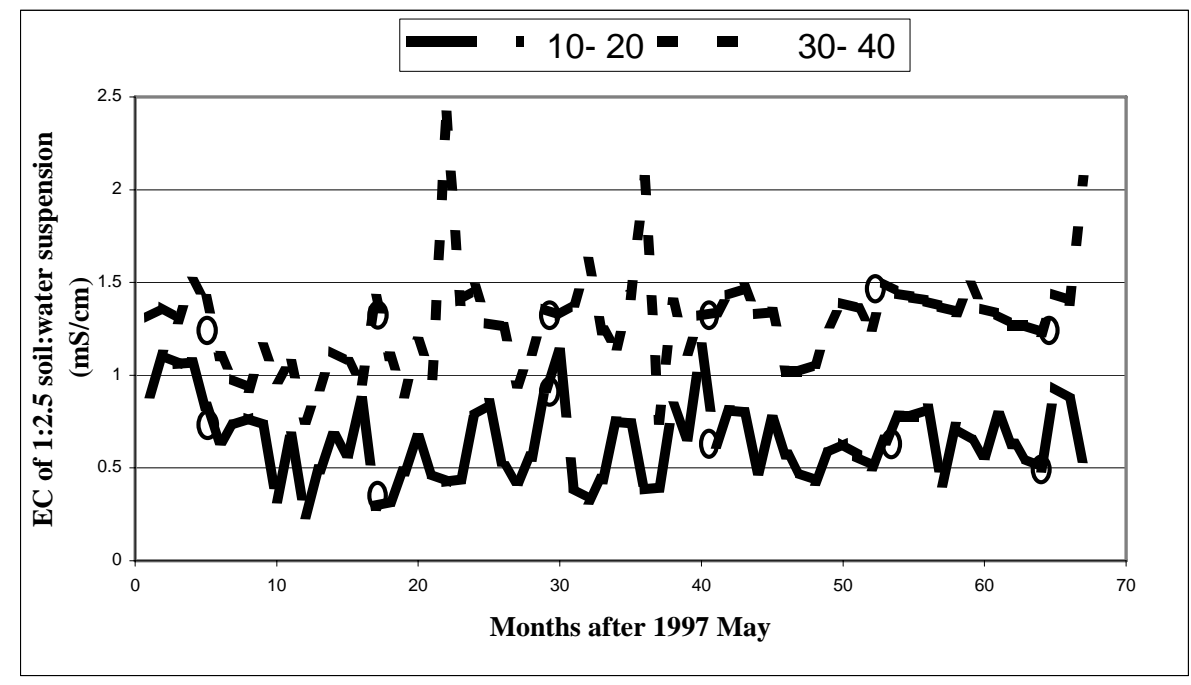

Fig. 3

Pattern of monthly salinity (EC2.5) changes in the 10-20 cm (second) and 30-40 cm (third) genetic horizon of a crusty meadow solonetz (Apaj, Hungary) located in a homogeneous grassland with the indication (O) of each October sampling between 1997 and 2002 
between $-65 \%$ and $+15 \%$, and in the third horizon between $+6 \%$ and $-6 \%$ (!) as compared to the first year (Fig. 3). A greater fluctuation was observed for the monitored points than in the case of our independent study.

For quantitatively treating the data eight temporal patterns of yearly soil salinity changes were determined based on the second and third genetic horizon, as shown in Table 1: pattern " $\Lambda$ " meaning a peak in one of the middle years, pattern " $M$ " corresponds to fluctuations with two "highs" with one "low" between, just like pat-

A

I 4009 Hajdú-Bihar

Crusty Meadow Solonetz, Berettyószentmárton

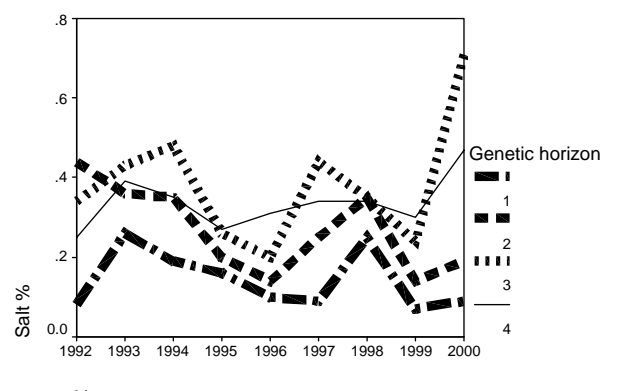

Year
B

I 4403 Bács-Kiskun

Solonchak-Solonetz, Szabadszállás

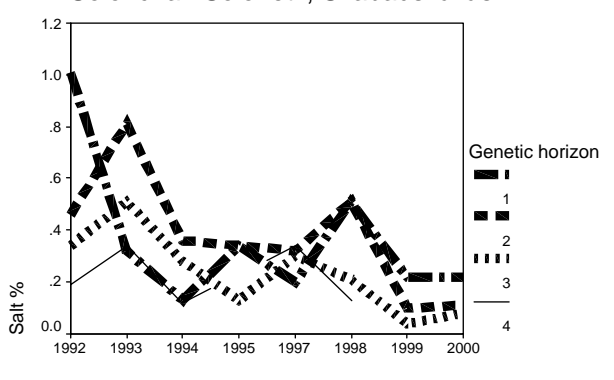

Year

Fig. 4

Peaky "W" (A) and continuous decreasing "" (B) pattern of yearly soil salinity changes

terns "N" and "W" (Fig. 4A). Pattern "I" corresponds to continuous decrease (Fig. 4B), pattern "-" to stagnating, and pattern "/" to continuous increase in salinity during the studied period.

The analysis of the association between the patterns of yearly soil salinity changes and other qualitative variables was carried out using Correspondence Analysis (BENZECRI, 1992), which is an exploratory technique having no assumption on the distribution of the variables.

\section{Results and Discussion}

There were great differences in the average temperature (Fig. 5A) and sums of precipitation (Fig. 5B.) between the years. Very dry and wet years and cooler and warmer years followed each other.

Differences were also found between the pattern of groundwater level changes measured in the observation wells, as shown by Fig. 6 . The depth of the groundwater level fluctuated in the range considered as the "critical level" of groundwater for causing salt accumulation in the soils. During the dry years the groundwater level stagnated or decreased, but in the wet years a rise occurred in the groundwater level, the largest ones at Kecskemét and Szeged. The correlation between all combinations of the variables of groundwater level, irradiation, mean temperature and 
A

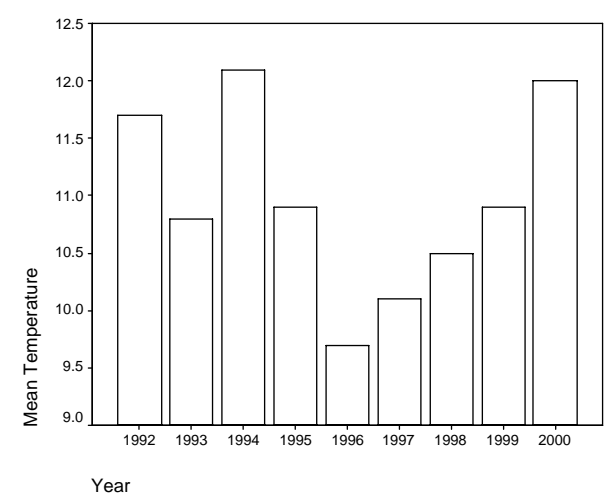

B

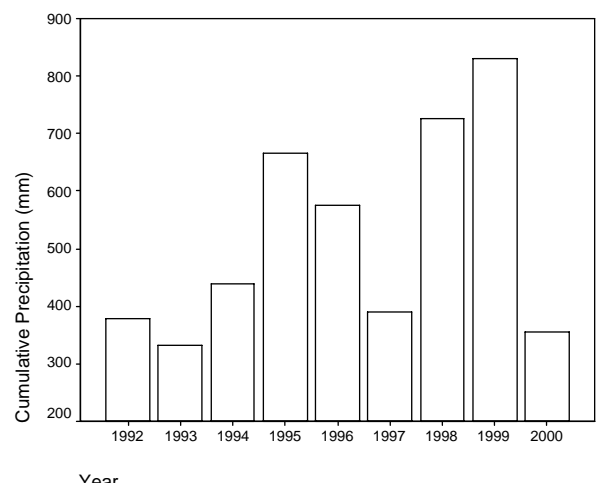

Year

Fig. 5

Yearly mean temperature (A) and sum of precipitation (B) during the studied years (19922000) at Szolnok, in the centre of the Great Hungarian Plain

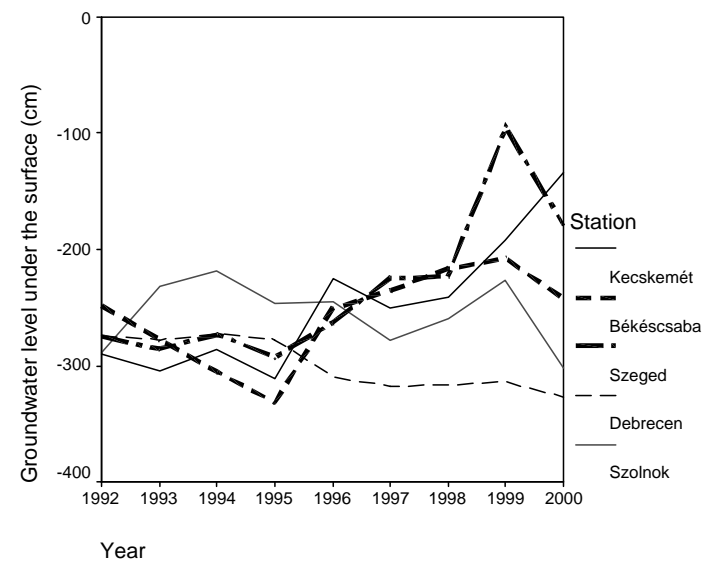

Fig. 6

Change in groundwater level at the observation stations during the studied years (1992-2000)

precipitation were as expected and statistically significant at 0.01 level (data not given), which indicates the strong meteorological control of shallow groundwater level.

Fig. 7 illustrates the distribution of the different patterns of yearly soil salinity changes. Although some tendencies are visible, it is difficult to make a quantitative assessment of the distributions. Correspondence analysis established a weak correlation between the pattern of salinity and groundwater stations. The biplot given on Fig. 8 demonstrates nevertheless that the decreasing (")") yearly salinity pattern is characteristic in the region around Kecskemét, while the increasing ("/) yearly sal- 


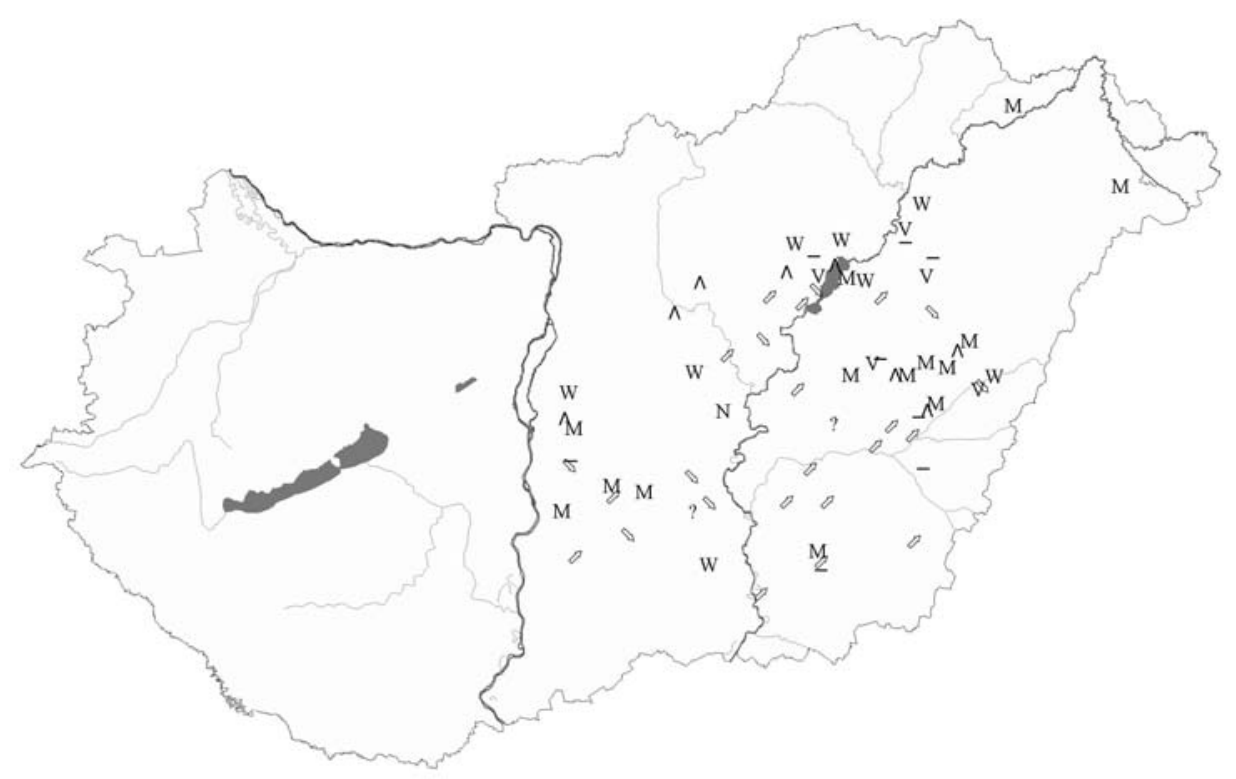

Fig. 7

Distribution of the patterns of yearly soil salinity changes over the Great Hungarian Plain.

inity pattern is found mainly around Békéscsaba. Most of the other areas have fluctuating or stagnant patterns of yearly salinity changes.

The association of soil types with the pattern of yearly soil salinity changes (Table 2) was also weak. What was remarkable is that the increasing pattern "" is most characteristic in the solonetzic meadow soil type.

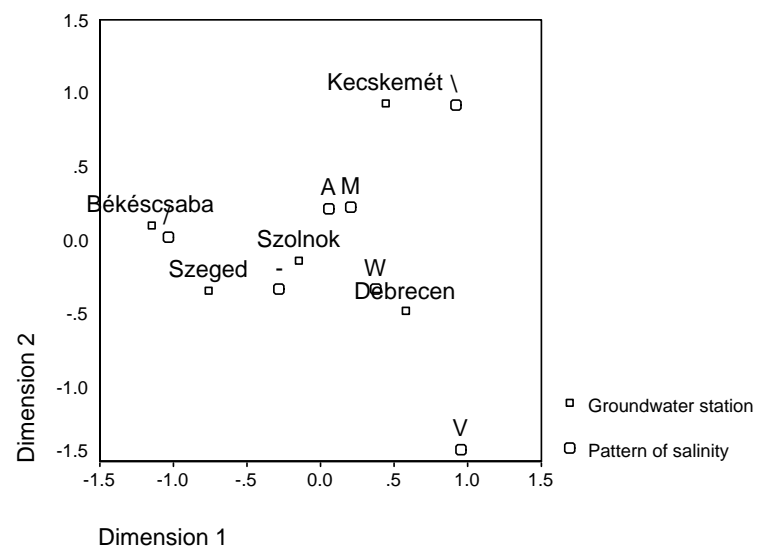

Fig. 8

Biplot correspondence map of groundwater observation stations and patterns of yearly soil salinity changes 


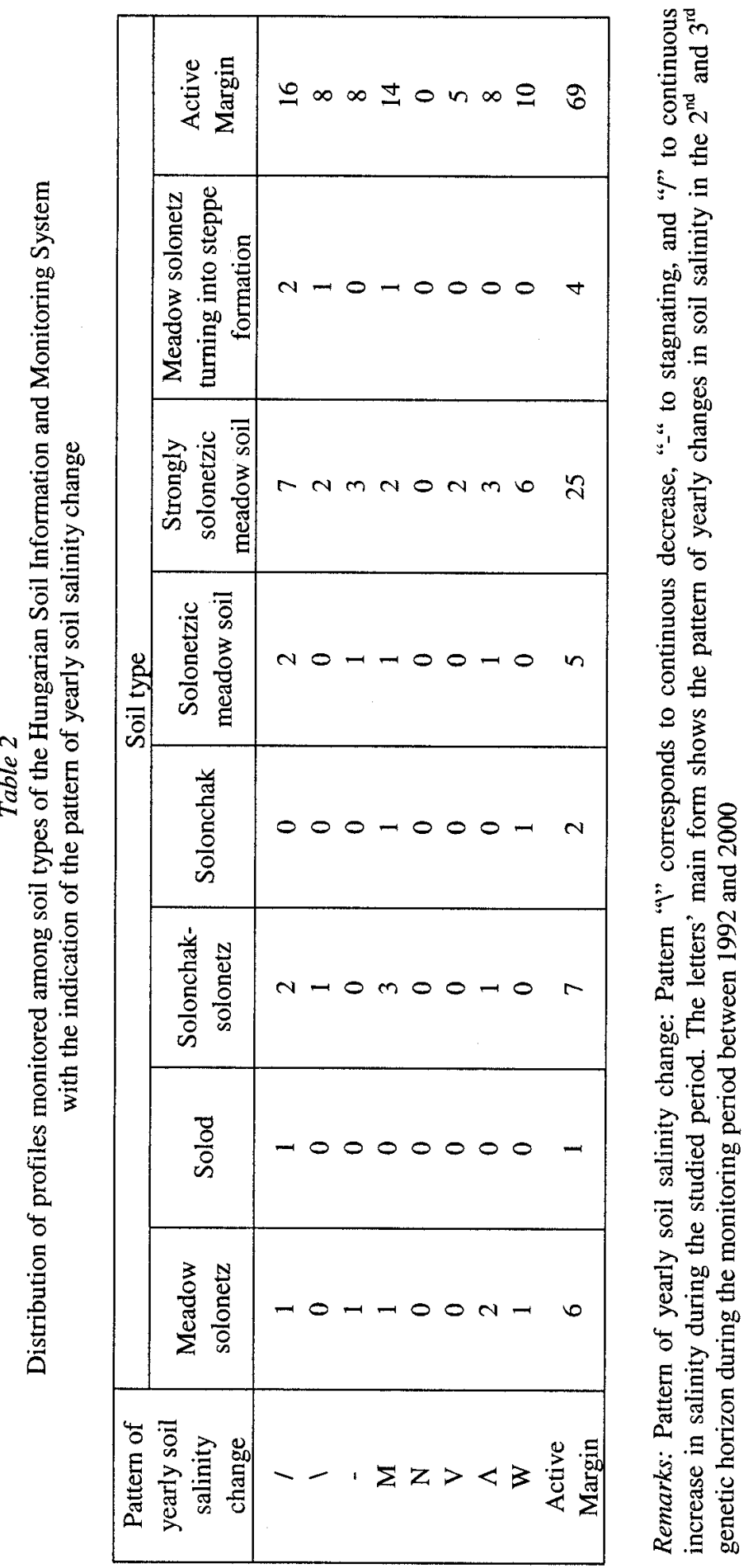


As a final remark, it should be admitted that in the curves (such as shown by Fig. 4) additional scatter occur as compared to Fig. 3, which is due to the varying number of points sampled in the different years' field campaign. Furthermore, it cannot be disregarded that the distance from the meteorological stations and groundwater observation wells decreased the correlation with the salinity. These facts must be considered when deciding the optimal set of predictive variables for salinity changes.

\section{Summary}

The statistical analysis of salinity data from samples collected yearly from genetic soil horizons of 69 points of the Hungarian Soil Information and Monitoring System between 1992 and 2000 showed changes in time. There is a strong atmospheric control over the groundwater level and the resulting soil salinity. Weak statistical association was established between either the pattern of yearly soil salinity changes in the second $(10-20 \mathrm{~cm})$ and third $(30-40 \mathrm{~cm})$ genetic horizon and the groundwater observation stations or the soil types. In the area of Kecskemét there was a tendency of decreasing soil salinity patterns, while around Békéscsaba a tendency of increasing soil salinity patterns, as illustrated by the correspondence biplot.

Regarding soil types, the solonetzic meadow soil showed a tendency of increasing salinity. It was concluded that the statistical analyses of the monitored data must be carefully planned in order to provide the optimal background data as independent data from all those available to accompany the monitored soil data as dependent variable.

The presented work was supported by the Hungarian National Scientific Research Fund (OTKA, T37731) and by the National Research and Development Programme under OM-4/015/2004 NKFP and GVOP (AKF) - 2004 - 3.1.1 grants.

Key words: salinity, monitoring, genetic soil horizon, correlation, temporal change

\section{References}

BenZeCRI, J. P., 1992. Correspondence Analysis Handbook. Dunod. Paris.

DARAB, K., 1967. Remarks to the article of H. Franz "Data on the Quaternary stratigraphy and the formation of salt-affected soils in Hortobágy and its neighbourhood". (In Hungarian) Agrokémia és Talajtan. 16. 459-468.

Fullerton, S. \& PAWLUK, S., 1987. The role of seasonal salt and water fluxes in the genesis of solonetzic B horizons. Canadian Journal of Soil Science. 67. 719-730.

GATES, T. K. et al., 2002. Monitoring and modeling flow and salt transport in a salinitythreatened irrigated valley. Journal of Irrigation and Drainage Engineering. 128. 87-99. 
KovÁcs, D., Tóth, T. \& MARTH, P., 2006. Study of food chain element analogy: salinity/sodicity/alkalinity of Hungarian soils during a decade as shown by the National Soil Monitoring Network. Cereal Research Communications. 34. (1) 231-234.

MOLNÁR, Zs. \& BORHIDI, A., 2003. Hungarian alkali vegetation: Origins, landscape history, syntaxonomy, conservation. Phytocoenologia. 33. 377-408.

SzABOLCS, I., 1966. Methods of Large-scale Soil Genetic Type Mapping. (In Hungarian) OMMI. Budapest.

SzABOLCS, I., 1974. Salt-affected Soils in Europe. Martinus Nijhoff - The Hague, The Netherlands and RISSAC, Budapest.

TÓTH, T. \& BLASKÓ, L., 1998. Secondary salinization due to irrigation. In: The Soil as a Strategic Resource. (Eds.: Rodriguez Rodriguez, A., Jiménez Mendoza, C. C. \& Tejedor SAlguero, M. L.) 229-253. Geoforma Ediciones. Logrono

TÓTH, T. \& KUTI, L., 2002. Factors of the changes in soil salinity at Apaj, Kiskunság region. In: Soil and Environment. (Eds.: KÁTAI, J. \& JÁVOR, A.) (In Hungarian) 106-116. Debreceni Egyetem Agrártudományi Centrum. Debrecen.

VÁRAllyay, Gy., 1966. Salt balances of the soils in the Danube-Tisza Interfluve. I. Salt balances in natural (non-irrigated) lands. (In Hungarian) Agrokémia és Talajtan. 15. 423-447.

VÁRALlyay, GY. et al., 1995. Soil Information and Monitoring System. Methodology. (In Hungarian) Ministry of Agriculture. Budapest. 